\title{
Developing Critical Thinking Skills among Prospective Teachers through Teaching Educational Research Course: A Quasi Experimental Approach
}

\author{
${ }^{a}$ Ayesha Kanwal, ${ }^{\text {b }}$ Intzar Hussain Butt \\ ${ }^{a}$ PhD Scholar, University of Education, Lahore, Pakistan \\ Email: Ayesha.kanwallch@gmail.com \\ ${ }^{\mathrm{b}}$ Associate Professor, University of Education, Lahore, Pakistan \\ Email: ib@ue.edu.pk
}

\begin{tabular}{l}
\hline ARTICLE DETAILS \\
\hline History: \\
Accepted 26 October 2021 \\
Available Online December 2021 \\
\hline Keywords: \\
Critical Thinking Skills, \\
Prospective Teachers, \\
Intervention \\
\hline JEL Classification: \\
J24,
\end{tabular}

DOI: $10.47067 /$ real.v4i4.194

\begin{abstract}
The study aims to develop critical thinking skills among prospective teachers. The study was experimental in nature; quasi experimental approach was used to conduct the study. The population of the study was prospective teachers studying at master level. Sample of the study was 73 prospective teachers enrolled in the educational research course in two groups. The first was labeled as the control group, while one was labeled as the experimental group. To assess the critical thinking skills of prospective teachers test was developed by the research using guidelines of Watson and Glaser test. Test was consisted of five dimensions i.e. analyzing, assumptions, deduction, and inference and interpreting information. Cronbach's alpha determined the test's reliability to be 0.80 . Intervention was consisted of 10 lessons related to educational research course. The prospective teachers performed well in analyzing, Assumptions, deduction and overall CTS in post-test as compare to pre-test. There was statistically noteworthy the variation between the or before as well as post-test grades of Inference and interpreting. The critical thinking skills are essential element to compete 21st century challenges. Prospective teachers have to face many educational challenges to improve students learning, it is necessary that they should be prepared with CTS either to infuse through separate curriculum or embed with existing curriculum.
\end{abstract}

(C) 2021 The authors. Published by SPCRD Global Publishing. This is an open access article under the Creative Commons AttributionNonCommercial 4.0

Corresponding author's email address: Ayesha.kanwallch@gmail.com

\section{Introduction}

Thinking is a vital concept that has been highlighted from the origin of humanity. It may be summarized as asking reasonable questions of oneself in order to solve an issue using one's previous experiences and background. Problem solving, questioning, reflecting on, and critiquing an event are all mental activities that rely on making meaningful connections between concepts and events and reaching conclusions (Halpern, 2013). Critical thinking (CT) on the other hand, has been around since 
the 1930s, but its roots can be traced back to Socrates' time.It's defined as a technique of thinking as to somewhat theme, element, or issue in which the intellectually helps to improve the worth of his/her thoughtful by meticulously managing and enforcing intellectual norms on thought structures (Daniel \& Auric, 2011).

The foundations of CT literature may be found in two theoretical fields: philosophy and psychology (Lewis \& Smith, 1993). According to Lai (2011), these diverse academic strands have produced different approaches to define CT from several perspectives: philosophical, cognitive psychological and educational approach. By ancient and modern intellects, all used a logical approach in their writings. Instead of focusing on the actions or acts that a hypothetical critical thinker can perform, this technique focuses on the features and attributes of a hypothetical critical thinker.

CT is defined by Bailin (2002) as "high-quality thinking," or "excellent thinking" that meets specific sufficiency and accuracy standards or norms. A psychologist, Glaser (1942), describes critical thinking as an attitude and the rational application of abilities in problem-solving situations. The educational approach to CTS is the third method. In the area of education, Sternberg (1986) identified a third CTS strand. Those working in the sphere of education have also taken part in CTS debates. According to Lai (2011), Benjamin Bloom and his colleagues fall under this group. Whenever it comes to learning and studying higher-order thinking skills, their typology for information thinking processes is one of the most widely used sources for educators. Bloom's taxonomy is a systematic classification system that starts with comprehension and ends with evaluation. CT is commonly defined as the top three levels of analysis, synthesis, and assessment (Lai, 2011).

CTS entail the application of assumptions, knowledge, competency, and the ability to examine one's own thinking. It is characterized as intellectually engaged, skillful, and responsible thinking that promotes sound judgment. Critical thinking skills include self-correction, monitoring to determine the reasonableness of reasoning, and introspection. People who use critical thinking abilities are able to take a step back and evaluate the quality of their reasoning.

Popil (2011) stated that CT processes need active argumentation, effort, reasoning, conceptualizing, assessing complicated substitutes, and creating situational value judgments. Examining, differentiating, and analyzing information, as well as reflecting on the information that will be used to make judgments and affect professional decisions, are all part of CTS (Banning, 2006).

An important educational aim for our educational system and society as a whole is to develop students who are self-sufficient enough to think critically about academic subject matter and real-world situations. Fostering CTS is considered to be vital to providing a competent workforce in an increasingly complicated environment and maintaining a democratic society with an able thinking population (Tsui, 2002).

For that reason, the ultimate purpose of education has always been to educate higher order cognitive talents such as CTS. (Bailin \& Siegel, 2003). Whether CTS can be taught or not is a point of contention among psychologists and philosophers (Ornstein \& Hunkins, 2004). As a result, the ultimate objective of education has always been to educate higher order cognitive talents such as critical thinking ability (Bailin \& Siegel, 2003). Psychologists and philosophers differ in their beliefs as to whether CTS can be taught or cannot be taught, (Ornstein \& Hunkins, 2004). There is various methods to organize CTS instruction: we may teach a separate course or unit, include critical thinking into everything we teach, or adopt a mixed approach. The first method, which involves creating a distinct sequence or unit, 
needs resources that teach CT dispositions, abilities, and knowledge. The drawback is that little expertise from the programme or contents may be transferred to the remainder of the curriculum. Infusion, the second possible approach CT must be taught as an essential component of all subject areas (Wright, 2002).Teachers and counselors must first be motivated to CTS and its philosophy before they can implement it in their classrooms. According to research on CTS development, pupils' critical thinking improves as a result of education. According to the findings of the study, teachers and candidates have ordinary or low CTS (Yesil, \& Korkmaz). Abrami et al. (2015) found in a meta-analysis empirical research that when students were educated appropriately, they developed their critical thinking skills.

He also found that it is connected to pupils' achievement in a positive way. Junsay (2016) divided students into groups for an experimental research. The treatment group was taught through reflective learning, although the control group was taught through lecture process, and the reflective learning technique was shown in order to be far more effective for the progress of CT in prospective. Abramiet al. (2015) claimed that two instructional interventions are essential to promoting CTS (a) collaborative and cooperative learning, and (b) applying real-life examples, circumstances, and problems. When related studies are reviewed, it becomes clear that memorization and classroom teaching methods are to responsible for the low and average levels of critical thinking in our country's higher education institutions.

Furthermore, in order to promote CTS among learners, teachers must first develop their CTS. Teachers, who are critical thinkers, must be better equipped to educate their students to become critical thinkers (Paul \& Paul, 2010). Empirical research has shown that explicit education about thinking improves students' skills to understand and use thinking processes (Kong, 2006; Polat, 2015). With these findings, it is evident that more recent empirical findings, as well as experimental and mixedmethod research, are required. The objective of this article is to evaluate the usefulness of the instructional intervention in a classroom environment that allows students to freely express their opinions and help them in order to improve their CTS.

The study objectives were to:

1. Develop critical thinking skills among prospective teachers.

1.1 Assess CTS of prospective teachers before teaching educational research course.

1.2 Assess CTS of prospective teachers after teaching educational research course.

\section{Research Hypotheses}

- Ho: There was no statistically significant difference in CT skills before and after teaching educational research course in prospective teachers.

\section{Material and Methods}

The paradigm of the study was positivism with quantitative research design. The study was experimental in nature; quasi pre \& post strategy was designated for the study. In each group 41 prospective teachers were enrolled studying educational research course in the Public University, Lahore, and Punjab, Pakistan. The study sample was divided into two groups i.e. control and experiment group. In control group 38 prospective teachers while 35 prospective teachers were in experimental group. To assess the critical thinking skills test was developed by researcher with the help of experts. Instrument of the study was consisted of five CTS, each skill contain eight statements. The Cronbach alpha value was o.80. To develop CTS, instructional intervention was developed by the researcher. The intervention was conducted for one semester (18 weeks). The intervention was in form 
of 10 lessons. Pre-test was conducted one week before starting the intervention from control and experiment groups. Post-test was conducted at the end of intervention from both control and experiment groups.

\section{Data Analysis and Interpretation}

Objective: 1.1 to assess critical thinking skills of prospective teachers before teaching research method course.

Table 1: Means, SDs of control and experimental groups on pre-test scores on critical thinking skills

\begin{tabular}{|c|c|c|c|c|c|c|c|}
\hline & \multicolumn{2}{|c|}{ Control } & \multicolumn{2}{|c|}{ Experimental } & \multicolumn{2}{|c|}{$\begin{array}{l}\text { Independent } \\
\text { samples t-test }\end{array}$} & \\
\hline & $M$ & $S D$ & $M$ & $S D$ & $\mathrm{t}$ & $\mathrm{p}$ & Cohen'd \\
\hline Analyzing & 61.28 & 14.47 & 59.76 & 15.44 & -0.46 & 0.646 & 0.10 \\
\hline Assumptions & 47.87 & 14.23 & 46.34 & 17.06 & -0.44 & 0.662 & 0.10 \\
\hline Deduction & 43.29 & 12.84 & 42.68 & 19.16 & -0.17 & 0.866 & 0.04 \\
\hline Inference & 28.05 & 15.76 & 26.83 & 16.19 & -0.35 & 0.731 & 0.08 \\
\hline Interpreting & 48.78 & 12.44 & $53 \cdot 35$ & 12.51 & 1.66 & 0.101 & 0.37 \\
\hline Total CTS & $47 \cdot 32$ & 3.28 & 46.83 & 7.75 & -0.37 & 0.712 & 0.09 \\
\hline
\end{tabular}

Note. Cohen'd vary from 0.2 to 0.8 , $0.2=$ small, $0.5=$ medium, $0.8=$ Large effect size

Table 1 shows analysis of pre-scores of experimental and control groups on CTS. Independent samples t-test was used to compare pre-scores of experimental and control group skills i.e. analyzing, assumptions, deduction, inference, interpreting and Total CTS. Results of inferential t-test show that no statistically noteworthy ( $\mathrm{p}>.05$ ) variance in mean scores control group and experimental group of CTS i.e. analyzing, assumptions, deduction, inference, interpreting and Total CTS.

Figure 1: Pre-test means scores of control and experimental groups of critical thinking skills

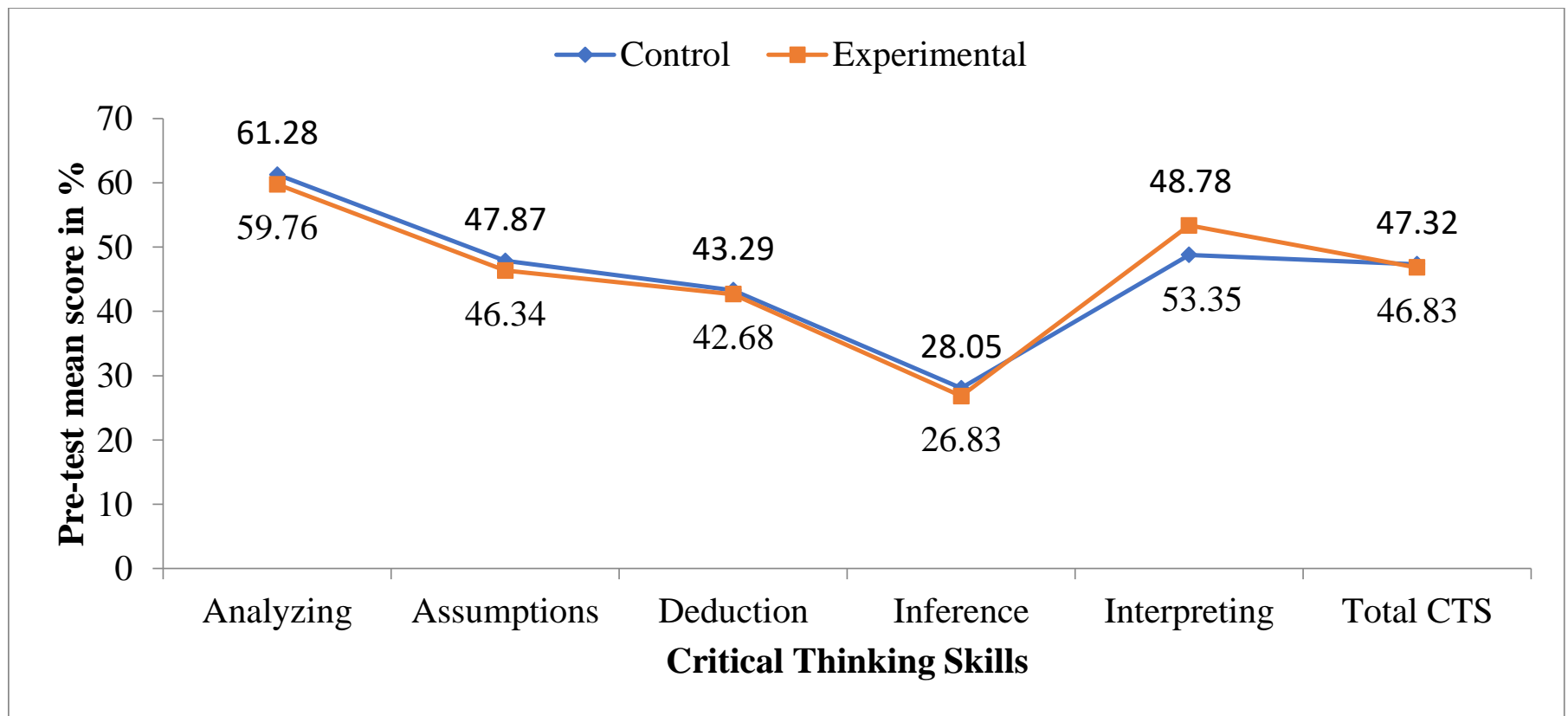

Note. Critical thinking pre-test scores of prospective teachers in control and experimental groups studying in Public Sector University 
Objective: 1.2 to assess critical thinking skills of prospective teachers after teaching research method course.

Table 2: Means, SDs of control and experimental groups on post-test scores

\begin{tabular}{|l|l|l|l|l|l|l|l|l|l|}
\hline & \multicolumn{2}{|l|}{ Control } & \multicolumn{3}{|l|}{$\begin{array}{l}\text { Independent samples } \\
\text { t-test }\end{array}$} \\
\hline & $M$ & $S D$ & & $M$ & $S D$ & & $\mathrm{t}$ & $\mathrm{p}$ & \multicolumn{3}{l|}{ Cohen'd } \\
\hline Analyzing & 61.59 & 15.15 & & 69.21 & 14.55 & & 2.32 & $.023^{*}$ & 0.51 \\
\hline Assumptions & 45.12 & 16.27 & & 55.18 & 15.81 & & 2.84 & $.006^{*}$ & 0.63 \\
\hline Deduction & 46.04 & 18.63 & & 54.27 & 15.96 & & 2.15 & $.035^{*}$ & 0.48 \\
\hline Inference & 29.57 & 17.17 & & 51.40 & 16.33 & & 0.49 & .622 & 0.11 \\
\hline Interpreting & 52.44 & 19.41 & & 56.71 & 17.70 & & 1.04 & .301 & 0.23 \\
\hline Total CTS & 47.99 & 8.57 & & 54.76 & 5.70 & & 4.21 & $<.001^{*}$ & 0.95 \\
\hline
\end{tabular}

Note. ${ }^{*} \mathrm{p}<.05$, Cohen'd vary from 0.2 to 0.8 , $0.2=$ small, $0.5=$ medium, $0.8=$ Large effect size

Table 2 shows analysis of post-test scores of control and experimental groups on CTS. Independent samples t-test was conducted to compare post-test scores of control group and experimental group skills i.e. analyzing, assumptions, deduction, inference, interpreting and total CTS. Results of inferential t-test have shown statistically noteworthy $(\mathrm{p}<.05)$ variance in mean scores of control and experimental group of CTS i.e. analyzing, assumptions, deduction and total CTS. The control group's mean analyzing score $(M=61.59, \mathrm{SD}=15.15)$ was lower than the experimental group's mean analyzing score $(M=69.21, S D=14.55)$. The mean score of the control group's assumptions $(\mathrm{M}=45.12, \mathrm{SD}=16.27)$ was lower than the mean score of the experimental group's assumptions $(M=55.18, S D=15.81)$. The control group's mean deduction score $(M=46.04, S D=18.63)$ was lower than the experimental group's mean deduction score $(M=54.27, S D=15.96)$. The control group's mean total CTS score $(M=47.99, S D=8.57)$ was lower than the experimental group's mean score $(M=54.76$, $\mathrm{SD}=5.70$ ). Results of inferential t-test have shown no statistically noteworthy ( $p>.05$ ) variance in mean scores control group and experimental group of CTS i.e. inference and interpreting information. Effect size of analyzing (0.51), assumptions (0.63), and deduction (0.48) is medium and effect size of Total CTS (0.95) is large and effect size of inference (0.11), interpreting (.23) is small. 
Figure 2: Post-test means scores of control and experimental groups of critical thinking skills

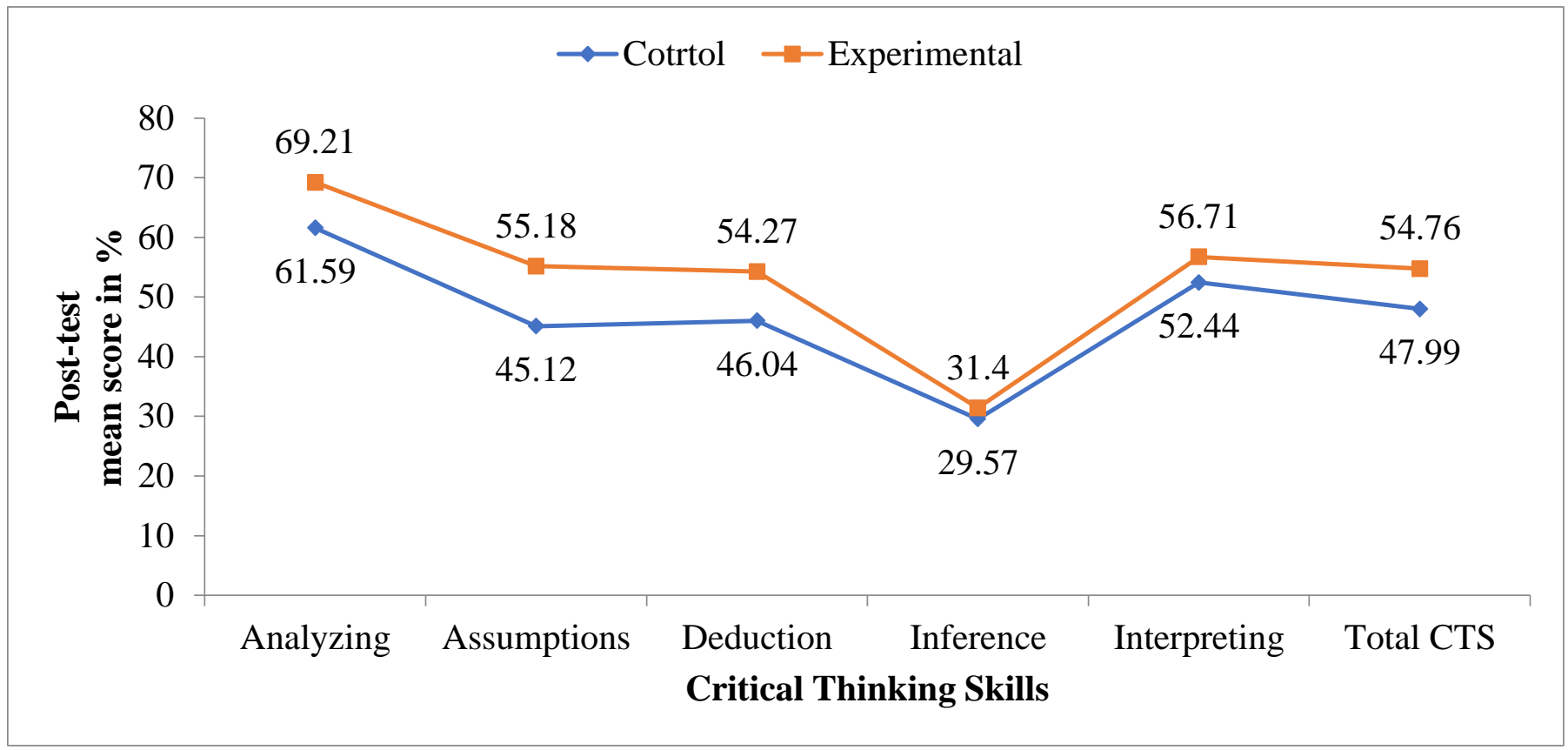

Note. Critical thinking post-test scores of prospective teachers in control and experimental groups studying in Public Sector University

Table 3: Means, SDs of pre-test and post-test of control groups

\begin{tabular}{|l|l|l|l|l|l|l|l|l|l|}
\hline & \multicolumn{2}{|l|}{ Pre-test } & \multicolumn{3}{l|}{ Post-test } & \multicolumn{3}{l|}{ Paired samples t-test } & \\
\hline & $M$ & $S D$ & & $M$ & $S D$ & & $\mathrm{t}$ & $\mathrm{p}$ & Cohen'd \\
\hline Analyzing & 61.28 & 14.47 & & 61.59 & 15.15 & & -0.09 & .928 & 0.02 \\
\hline Assumptions & 47.87 & 14.23 & & 45.12 & 16.27 & & 0.89 & .377 & 0.18 \\
\hline Deduction & 43.29 & 12.84 & & 46.04 & 18.63 & -0.74 & .462 & 0.17 \\
\hline Inference & 28.05 & 15.76 & & 29.57 & 17.17 & & -0.39 & .700 & 0.09 \\
\hline Interpreting & 48.78 & 12.44 & & 52.44 & 19.41 & -1.04 & .306 & 0.23 \\
\hline Total CTS & 47.32 & 3.28 & & 47.99 & 8.57 & & -0.40 & .693 & 0.11 \\
\hline
\end{tabular}

Note. Cohen'd vary from 0.2 to 0.8 , $0.2=$ small, $0.5=$ medium, $0.8=$ Large effect size

Table 3 provides a comparison of control's pre- and post-test results on the CTS. To compare pre-test and post-test scores of control group CTS i.e. analyzing, assumptions, deduction, inference, interpreting and total CTS, paired samples t-test was conducted. The results demonstrate that no measurable variance ( $\mathrm{p}>.05$ ) between the pre and post-test of the control group's CTS, which included analyzing, assumptions, deduction, inference, interpretation, and overall CTS. 
Figure 3: Pre-test and post-test means scores of control group of critical thinking skills

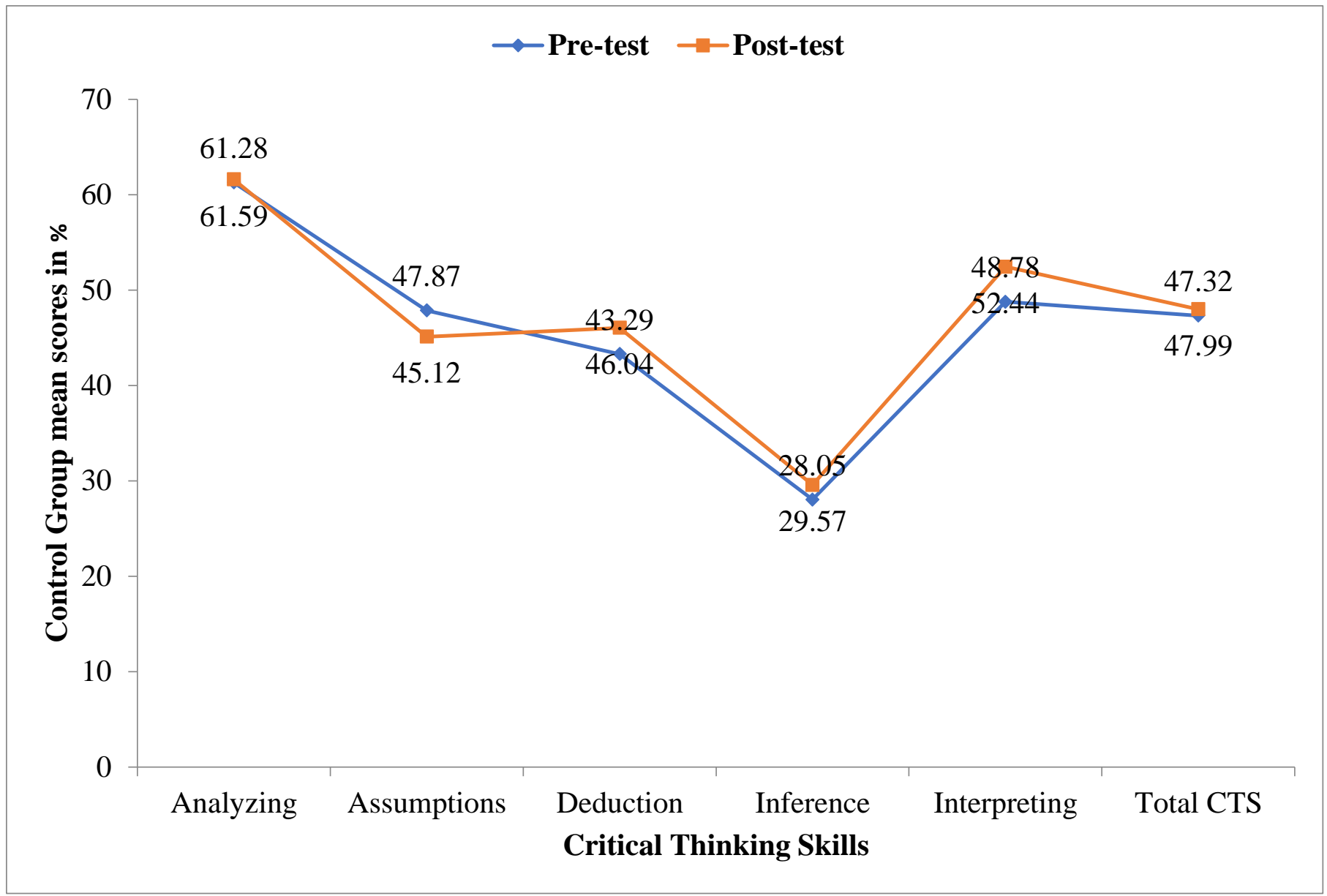

Note. Critical thinking pre-test and post-test scores of prospective teachers in control group studying in Public Sector University

Table 4: Means, SDs of pre-test and post-test of experimental groups

\begin{tabular}{|c|c|c|c|c|c|c|c|}
\hline & \multicolumn{2}{|c|}{ Pre-test } & & Post-test & \multicolumn{2}{|c|}{ Paired samples t-test } & \\
\hline & $M$ & $S D$ & $M$ & $S D$ & $\mathrm{t}$ & $\mathrm{p}$ & Cohen'd \\
\hline Analyzing & 59.76 & 15.44 & 69.21 & 14.55 & -3.17 & $.003^{*}$ & 0.63 \\
\hline Assumptions & 46.34 & 17.06 & 55.18 & 15.81 & -2.70 & $.010^{*}$ & 0.54 \\
\hline Deduction & 42.68 & 19.16 & 54.27 & 15.96 & $-3 \cdot 50$ & $.001^{*}$ & 0.66 \\
\hline Inference & 26.83 & 16.19 & 31.40 & 16.33 & -1.53 & .133 & 0.28 \\
\hline Interpreting & 53.35 & 12.51 & 56.71 & 17.70 & -0.99 & 0.327 & 0.22 \\
\hline Total CTS & 46.83 & 7.75 & 54.76 & 5.70 & $-5 \cdot 38$ & $<.001^{*}$ & 1.18 \\
\hline
\end{tabular}

Note. ${ }^{*} \mathrm{p}<.05$, Cohen'd vary from 0.2 to 0.8 , $0.2=$ small, $0.5=$ medium, $0.8=$ Large effect size 
Table 4 shows analysis of pre-test and post-test scores of experimental groups on CTS. Paired samples t-test was showed to relate pre and post-test scores of experimental group skills i.e. analyzing, assumptions, deduction, inference, interpreting and total CTS. Results of paired samples t-test show that there was statistically significant $(\mathrm{p}<.05)$ difference in mean scores pre-test and post-test of experimental group on CTS i.e. analyzing, assumptions, deduction, and total CTS. The mean score of analyzing of pre-test $(\mathrm{M}=59.76, \mathrm{SD}=15.44)$ was less than mean score of analyzing on post-test of experimental group $(M=69.21, S D=14.55)$. The mean score of pre-test $(M=46.134, S D=17.06)$ was less than post-test of assumptions of experimental group $(\mathrm{M}=55.18, \mathrm{SD}=15.81)$. The mean score of pre-test $(M=42.68, S D=19.16)$ was less than post-test of deduction of experimental group $(M=54.27, S D=15.96)$. The mean score of total CTS of pre-test $(M=46.83, \mathrm{SD}=7.75)$ was less than mean score of post-test of total CTS of experimental group $(M=54.76, S D=5.70)$. Results of independent samples t-test show that there was no statistically significant $(\mathrm{p}>.05)$ variance in mean scores pre and post-test of CTS i.e. inference and interpreting information. Effect size of analyzing (0.63), assumptions (0.54), and deduction (o.66) is medium and effect size of Total CTS (1.18) is very large and effect size of inference (o.28), interpreting (.22) is small.

Figure 4: Pre-test and post-test means scores of experimental group of critical thinking skills

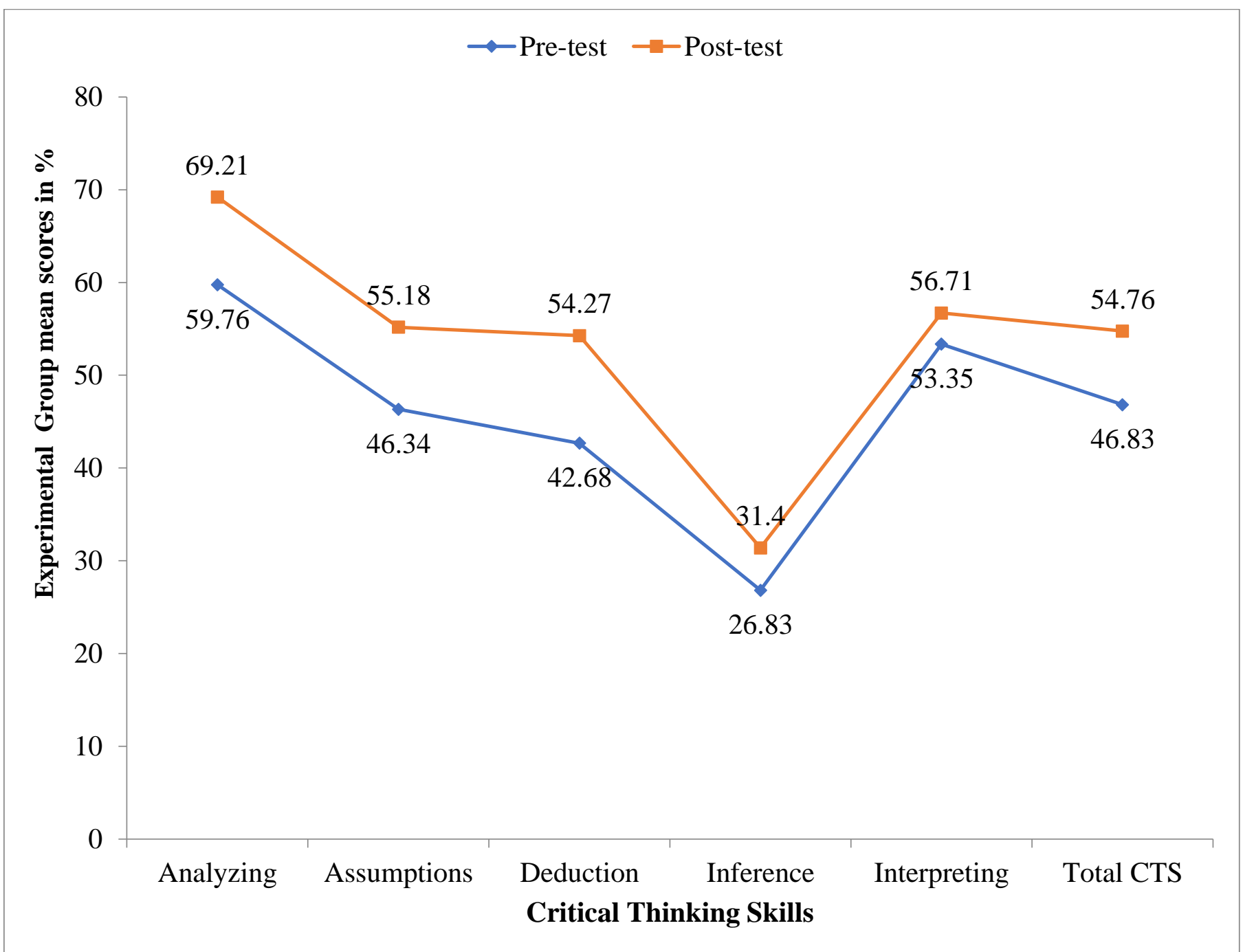

Note. Critical thinking pre-test and post-test scores of prospective teachers in experimental group studying in Public Sector University 
Table 5: Summary One-way ANCOVA: Effect of Intervention on Post-test scores after control effect of pre-test scores

\begin{tabular}{|c|c|c|c|c|c|c|}
\hline SOV & Type III SS & $\mathrm{df}$ & Mean Square & $\mathrm{F}$ & p. & Partial $\eta^{2}$ \\
\hline Pre-test score analyzing & $99 \cdot 33$ & 1 & $99 \cdot 33$ & .447 & .506 & .006 \\
\hline Group (Exp., Control) & 1223.415 & 1 & 1223.42 & 5.506 & $.021 *$ & .065 \\
\hline Error & 17553.110 & 79 & 222.19 & & & \\
\hline Total & 369531 & 82 & 369531 & & & \\
\hline Pretest score Assumptions & 668.436 & 1 & 668.436 & 2.652 & .107 & .032 \\
\hline Group (Exp., Control) & 2187.141 & 1 & 2187.141 & 8.678 & $.004^{*}$ & .099 \\
\hline Error & 19910.832 & 79 & 252.036 & & & \\
\hline Total & 228906.250 & 82 & & & & \\
\hline Pre-test score deduction & 301.918 & 1 & 301.918 & 1.003 & .320 & .013 \\
\hline Group (Exp., Control) & 1413.219 & 1 & 1413.219 & 4.696 & $.033^{*}$ & .056 \\
\hline Error & 23775.825 & 79 & 300.960 & & & \\
\hline Total & 231718.750 & 82 & & & & \\
\hline Pre-test score inference & 102.707 & 1 & 102.707 & .363 & .549 & .005 \\
\hline Group (Exp., Control) & 75.126 & 1 & 75.126 & .265 & .608 & .003 \\
\hline Error & 22359.183 & 79 & 283.028 & & & \\
\hline Total & 98750.000 & 82 & & & & \\
\hline Pre-test interpreting & 16.247 & 1 & 16.247 & .047 & .830 & .001 \\
\hline Group (Exp., Control) & 333.628 & 1 & 333.628 & .956 & .331 & .012 \\
\hline Error & 27582.838 & 79 & 349.150 & & & \\
\hline Total & 272187.500 & 82 & & & & \\
\hline Pre-test total score & 118.063 & 1 & 118.063 & 2.264 & .136 & .028 \\
\hline Group (Exp., Control) & 910.088 & 1 & 910.088 & 17.452 & $<.001^{*}$ & .181 \\
\hline Error & 4119.742 & 79 & 52.149 & & & \\
\hline Total & 221581.250 & 82 & & & & \\
\hline
\end{tabular}

Note. ${ }^{*} \mathrm{p}<.05$

Table 5 shows one-way ANCOVA conducted to analyze the effect of intervention on Post-test scores after control effect of pre-test scores. ANCOVA is an extension of ANOVA, used to find difference between groups while statistically controlling additional continuous variables (Pallant, 2013)

\section{Discussion}

The study purpose was to develop CTS among prospective teachers through teaching research method course. CTS can be developed through many approaches; one of them is through teaching instructions. CTS can be infused through content of the subject. Research method is very essential course in teacher education programs, its purpose is to sensitize prospective teachers about researchable topics, draw conclusion from existing literature, develop arguments for rationale of research and analyze the data to answer the research questions. Research method course require more CTS as compare to other subjects. CT and reasoning are core competencies which required in graduate 
students, many researches indicate the lack of these skills in graduates (Wong, \& Kowitlawakul, 2020).CTS of prospective teachers were Prior the intervention, both the experimental and control groups were evaluated, which were below average in assumptions (Cont. Mean=47.87, Expt. Mean=46.34) deduction (Cont. Mean=43.29, Expt. Mean=42.68) and inference (Cont. Mean=28.05, Expt. Mean=26.83) but in analyzing (Cont. Mean=61.28, Expt. Mean=59.76) and interpreting information (Cont. Mean=48.78, Expt. Mean=53.35) were near to average. Similar results are supported by the study conducted in 2013 (Zhou et al., 2013). CTS of prospective teachers were assessed after the intervention in experiment groups which were above average in analyzing (Expt. Mean=69.21), assumptions (Expt. Mean=55.18), deduction (Expt. Mean=54.27) and in interpreting information (Expt. Mean=56.71). Mean score of overall CTS in experiment group were above average. Results show that post test score were statistically significant greater than pre-test scores. Many studies support the effect of intervention to develop CTS (Scott, Markert, \& Dunn, 1998; Magnussen, et al., 2000; Bartlett \& Cox 2002; Adam \& Manson 2014; Abrami et al. (2015; Junsay (2016).

\section{Conclusion}

Results of the study conclude that instructional intervention supported to raise the CTS of prospective teachers. In different studies, way of delivering lessons for developing CTS varies. The nature of teaching course, nature of lesson, use of instructions for lesson delivering, students classroom organization, way of conducting activities, students' motivation to participate in different activities, student teacher interaction during teaching learning process varies from study to study. These factors may play the role as extraneous variables. It is a fact that CTS were developed after instructional intervention but it is not clear which component of instructional intervention worked more or less in developing CTS.

\section{Recommendation}

Most of the experimental studies reveals the noteworthy variance in pre and posttest but unable to identify the contribution of different factors. For this purpose qualitative study can be conducted to find the effect which is not detectable through experiment study.

\section{References}

Abrami, P. C., Bernard, R. M., Borokhovski, E., Waddington, D. I., Wade, C. A., \& Persson, T. (2015). Strategies for teaching students to think critically: A meta-analysis. Review of Educational Research, 85(2), 275-314.

Adam, A., \& Manson, T. M. (2014). Using a pseudoscience activity to teach critical thinking. Teaching of Psychology, 41(2), 130-134.

Bailin, S. (2002). Critical thinking and science education. Science \& Education, 11(4), 361-375.

Bailin, S., \& Siegel, H. (2003). Critical thinking. N. Blake, P. Smeyers, R. Smith \& P. Standish.

Banning M. (2006). Measures that can be used to instill critical thinking in nurse prescribers. Nurse Education in Practice, 6, 98-105.

Bartlett, D., \& Cox, P. D. (2002). Measuring change in students' critical thinking ability: implications for health care education. Journal of allied health, 31(2), 64-69.

Daniel, M. F., \& Auriac, E. (2011). Philosophy, critical thinking and philosophy for children. Educational Philosophy and Theory, 43(5), 415-435.

Glaser, E. M. (1942). An experiment in the development of critical thinking. Teachers College Record, 43(5), 409-410. Retrieved from http://www.tcrecord.org

Halpern, D. F., \& Riggio, H. R. (2013). Thinking critically about critical thinking: A workbook to accompany Halpern's thought \& knowledge. Routledge. 
Junsay, M. L. (2016). Reflective learning and prospective teachers' conceptual understanding, critical thinking, problem solving, and mathematical communication skills. Research in Pedagogy, 6(2), 43-58

Kong, S. L. (2006). Effects of a Cognitive-Infusion Intervention on Critical Thinking Skills and Dispositions, paper presented at the AARE Annual Conference, Andaide

Lai, E. R. (2011). Critical thinking: A literature review. Retrieved in 2012, March, from www.pearsons.com/hai/.../CriticalThinkingReviewFINA

Lewis, A., \& Smith, D. (1993). Defining higher order thinking. Theory into Practice, 32(3), 131-137.

Magnussen, L., Ishida, D., \& Itano, J. (2000). The impact of the use of inquiry-based learning as a teaching methodology on the development of critical thinking.

Ornstein, A. C., \& Hunkins, F. P. (2004). Curriculum: Foundations, principals and issues (4th ed.). Boston: Allyn \& Bacon.

Pallant, J. (2013). SPSS survival manual. McGraw-hill education (UK)

Paul, R., \& Elder, L. (2010). Critical Thinking: Ethical Reasoning as Essential to Fairminded Critical Thinking, Part III. Journal of Developmental Education, 33(2), 40-41.

Polat, S. (2015). Content Analysis of the Studies in Turkey on the Ability of Critical Thinking. Educational Sciences: Theory and Practice, 15(3), 659-670.

Popil, I. (2011). Promotion of critical thinking by using case studies as teaching method. Nurse education today, 31(2), 204-207.

Scott, J. N., Markert, R. J., \& Dunn, M. M. (1998). Critical thinking: change during medical school and relationship to performance in clinical clerkships. Medical education, 32(1), 14-18.

Sternberg, R. J. (1986). Critical thinking: Its nature, measurement, and improvement National Institute of Education. Retrieved from http://eric.ed.gov/PDFS/ED272882.pdf.

Tsui, L. (2002). Fostering critical thinking through effective pedagogy. Journal of Higher Education, 73(6), 740-763

Wong, S. H. V., \& Kowitlawakul, Y. (2020). Exploring perceptions and barriers in developing critical thinking and clinical reasoning of nursing students: A qualitative study. Nurse Education Today, 95, 104600.

Wright, T. S. (2002). Definitions and frameworks for environmental sustainability in higher education. Higher education policy, 15(2), 105-120.

Yesil, R., \& Korkmaz, O. (2009). The impact of learning-teaching applications based on questioning upon students' critical thinking dispositions and levels.

Zhou, Q., Huang, Q., \& Tian, H. (2013). Developing students' critical thinking skills by task-based learning in chemistry experiment teaching. Creative Education, 4(12), 40. 